This item was submitted to Loughborough's Research Repository by the author.

Items in Figshare are protected by copyright, with all rights reserved, unless otherwise indicated.

\title{
Tuning crystal morphology of succinic acid using a polymer additive
}

\section{PLEASE CITE THE PUBLISHED VERSION}

https://doi.org/10.1021/acs.cgd.6b00465

\section{PUBLISHER}

(C) American Chemical Society (ACS)

\section{VERSION}

AM (Accepted Manuscript)

\section{PUBLISHER STATEMENT}

This work is made available according to the conditions of the Creative Commons Attribution-NonCommercialNoDerivatives 4.0 International (CC BY-NC-ND 4.0) licence. Full details of this licence are available at: https://creativecommons.org/licenses/by-nc-nd/4.0/

\section{LICENCE}

CC BY-NC-ND 4.0

\section{REPOSITORY RECORD}

Klapwijk, Anneke R., Elena Simone, Zoltan K. Nagy, and Chick C. Wilson. 2018. "Tuning Crystal Morphology of Succinic Acid Using a Polymer Additive". figshare. https://hdl.handle.net/2134/32091. 


\section{Tuning crystal morphology of succinic acid using a polymer additive}

Anneke R. Klapwijk ${ }^{a, b}$, Elena Simone ${ }^{c}$, Zoltan K. Nagy ${ }^{c, d}$ and Chick C. Wilson ${ }^{b, *}$

${ }^{a}$ EPSRC Centre for Innovative Manufacturing in Continuous Manufacturing and Crystallisation (CMAC) at the University of Bath, Bath BA2 7AY, UK.

${ }^{\mathrm{b}}$ Department of Chemistry, University of Bath, Bath BA2 7AY, UK.

${ }^{\mathrm{c}}$ Department of Chemical Engineering, Loughborough University, Loughborough LE11 3TU, UK.

${ }^{d}$ School of Chemical Engineering, Purdue University, West Lafayette IN 47907-2100, USA

*Corresponding author email: c.c.wilson@bath.ac.uk 


\section{ABSTRACT}

The effect of the triblock co-polymer, Pluronic P123 (PP123) on the growth of succinic acid crystals from aqueous solutions is reported at two batch process scales: $10 \mathrm{~mL}$ and $350 \mathrm{~mL}$. The presence of small quantities of PP123 dissolved in solution is shown to modify the crystal morphology from plate-like crystals to block-like crystals, in a fully reproducible manner. Increasing the quantity of polymer present, or the concentration of succinic acid used, produces needle-like crystals that are less favorable for processing. In-line process analytical tools (FBRM, PVM and Raman) were implemented for the larger volume batch processes, allowing the crystallization to be monitored in real-time. The effect of the polymer on the metastable zone width (MSZW) has also been determined in designing the crystallization experiments and is presented. In addition, the effect of the individual blocks of the co-polymer, poly(ethylene glycol) and poly(propylene glycol) on the crystal morphology was examined and these findings, together with face indexing and knowledge of the underlying crystal structure, have allowed a possible mechanism to be constructed for the interaction of the polymer with the crystal surface. This mechanism, involving interactions of the polymer with the growing crystal surface, is supported by subsequent re-crystallization experiments following washing of the block-like crystals with a non-polar solvent.

\section{INTRODUCTION}

Crystallization is a vital step in the manufacture of many pharmaceuticals and fine chemicals, of which a high proportion are produced as crystalline solids. In crystallization, control over particle attributes such as crystal morphology is important for the function and physical properties of a material as well as its downstream processing behavior in steps such as filtration, drying and compaction. For example, plate shaped crystals may be undesirable due to their tendency to pack 
as an impermeable layer on filter media resulting in poor efficiency in filtration and washing whereas block shaped crystals may filter more readily; ${ }^{1,2}$ block-like crystals are therefore generally more desirable. Specifically for pharmaceutical materials, crystal shape and size uniformity may also affect the dissolution properties of a drug and thus its bioavailability.

The shape (morphology) of a crystal is governed by the relative growth rates of its individual faces; a fast growing face will have a smaller area in comparison to a face that grows more slowly (here we define the growth of a face as the rate of crystal growth along the direction perpendicular to that face - the (100) face thus "grows along" the $a$-direction, for example). The growth rate of each crystal face is affected by the internal structure of the material as well as by external factors such as the choice of solvent, mixing conditions, degree of supersaturation, seeding and the presence of impurities such as structurally similar by-products or polymers. Impurities may disrupt crystal growth by adsorbing and inhibiting growth on fast growing crystal faces where hydrogen bonding acceptor or donor sites may be positioned. In the late nineties Kubota and Mullin proposed a model to quantitatively describe the rate of crystal growth in solution in the presence of impurities. The model is based on the pinning mechanism of Cabrera and Vermilyea for the inhibition of step advancement, considering one-dimensional adsorption of the impurities on the step lines. ${ }^{3-6}$ It has been successfully used to describe quantitatively the growth rate of both organic and inorganic compounds in the presence of impurities. ${ }^{7-9}$ Borsos et al. have recently developed a control strategy to tailor the shape of crystals of potassium dihydrogen phosphate using two different growth modifiers, aluminum sulphate and sodium hexametaphosphate. ${ }^{10,11}$

In some cases impurities are deliberately added to a crystallization to engineer the growth of crystals with a desired morphology (by inhibiting growth of selected faces); these are known as 
additives and they can be used to control the shape of the final crystals, ${ }^{12-16}$ their size ${ }^{17-20}$ and polymorphic form..$^{21,22}$

There is a broad array of examples of the effect of structurally similar additives on crystal morphology, ${ }^{23-32}$ including the well-known examples of urea crystallized in the presence of biuret ${ }^{33}$ and benzamide with benzoic acid. ${ }^{34}$ However, large quantities of these impurities may be required to yield the desired effect, and the structural similarity of these additives means that they can be susceptible to inclusion into the crystal lattice. ${ }^{24,35}$ This can be undesirable, especially if the additive compound is non-benign - in pharmaceuticals, for example, such additives may not be Generally Recognized As Safe (GRAS).

Control over crystal morphology can also be exerted by introducing non-size matched impurities, for example through use of polymer additives. Unlike the structurally similar case, polymer additives are unlikely to be incorporated into the final product due to their dissimilarity to the target material and their large size. The use of polymers in this context is also favored by the fact that they are commonly used as excipients in drug formulations, and are thus a frequent component in pharmaceutical processing. There are a number of examples in which polymer additives have been shown to affect the crystallization process: anti-solvent crystallization of salbutamol sulfate in the presence of small quantities of a polyvinylpyrrolidone (PVP K25) was found to modify the crystal morphology from needle-like crystals to block-like crystals with a lower aspect ratio, ${ }^{36}$ while Vetter et al. reported the effect of Pluronic F127 on the crystal growth rates of ibuprofen. ${ }^{37}$ The effect of hydroxypropyl methylcellulose (HPMC) and other polymeric additives on the crystallization of Ritonavir and Flutamide was also recently studied. ${ }^{38-42}$

Additives have also been shown to influence the solid form adopted by an API, for example affecting the polymorphic form adopted in the case of tolfenamic acid crystallized in the presence 
of a polymer additive, ${ }^{43}$ and in the reproducible formation of paracetamol form II in the presence of structurally similar or size matched compounds. ${ }^{44,45}$

In this study the effect of a triblock co-polymer, Pluronic P123 (PP123) on the crystal morphology of succinic acid via cooling crystallization at $10 \mathrm{~mL}$ and $350 \mathrm{~mL}$ scale is reported. The effect of different stirring regimes (magnetic and overhead) is also investigated, together with the effect on the MSZW in the presence of the polymer additive, which is important for the full optimization of a crystallization process. Process analytical technology (PAT) tools, including Raman, FBRM (focused beam reflectance measurements) and PVM (particle vision and measurement), were implemented in this study at $350 \mathrm{~mL}$ scale to detect nucleation and observe crystal growth in situ. Such PAT methods are of increasing interest for crystallization processes, with a view to optimizing these as a vital part of the manufacturing chain for high value fine chemicals and pharmaceuticals.

\section{EXPERIMENTAL - MATERIALS AND METHODS}

Succinic acid, Pluronic P123, Pluronic F127 and poly(propylene glycol) 4000 (PPG4000) were obtained from Sigma Aldrich and poly(ethylene glycol) 1000 (PEG1000) was obtained from Alfa Aesar. Deionized water was used as the solvent for all crystallizations.

Succinic acid is a dicarboxylic acid used in the food industry and is a GRAS compound ${ }^{46}$ commonly used as a co-former in multi-component crystallization of APIs and other functional molecular systems. There are two reported polymorphic forms of succinic acid. The triclinic $\alpha-$ form ${ }^{47}$ is accessed through melt crystallization; there are no reports of its preparation by solution techniques and it is only stable above $137^{\circ} \mathrm{C} .{ }^{48}$ The monoclinic $\beta$-form may be obtained from various solvents and previous studies have shown that its crystal morphology can depend upon the solvent from which it is crystallized. Aqueous crystallization results in plate-like crystals whereas 
crystallization from isopropanol results in a more needle-like morphology. ${ }^{49,50} \mathrm{PP} 123$ belongs to a family of triblock co-polymers composed of a hydrophobic chain of poly(propylene glycol) flanked by two hydrophilic chains of poly(ethylene glycol) where the composition of PEG and PPG blocks is $\mathrm{PEG}_{20} \mathrm{PPG}_{70} \mathrm{PEG}_{20}$. The structures of succinic acid and PP123 are shown in Figure 1.<smiles>O=C(O)CCC(=O)O</smiles>

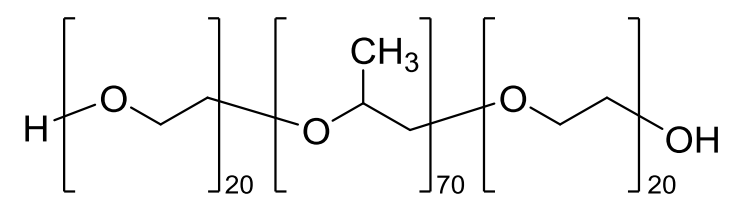

Figure 1. Succinic acid (left) and Pluronic P123 (right)

Solubility and MSZW measurements of succinic acid in water and in the presence of $0.5 \%$ PP123 in water were carried out using the Technobis Crystalline at $3 \mathrm{~mL}$ scale. The Crystalline uses turbidity and in-line imaging to detect the dissolution and nucleation points of a solution during temperature cycling. Vials containing different concentrations of succinic acid and polymer were cycled through temperature ranges between $5{ }^{\circ} \mathrm{C}$ and $70{ }^{\circ} \mathrm{C}$ using a heating/cooling rate of $0.5{ }^{\circ} \mathrm{C} \mathrm{min}{ }^{-1}$ using magnetic stirring at $400 \mathrm{rpm}$. The data were analyzed using CrystalClear software version 1.0.1.614. 


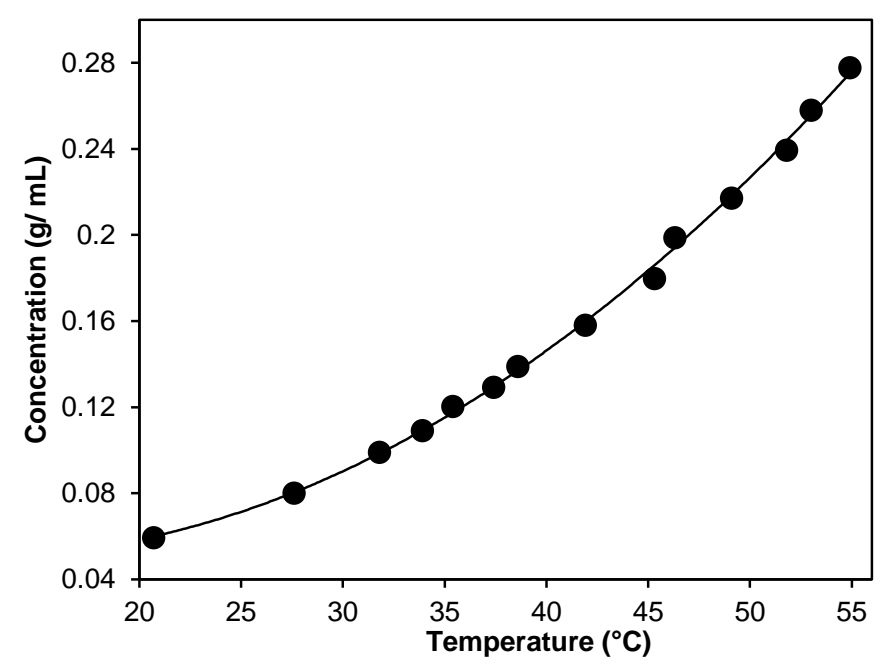

Figure 2. Solubility of succinic acid in water determined with the Technobis Crystalline. The line (a quadratic fit curve) is a guide to the eye.

Figure 2 shows the solubility of succinic acid in water. It was found that in the presence of the low concentrations of PP123 used, the solubility of succinic acid in water was unchanged regardless of the type of stirring and the concentration of the PP123. The solubility curve initially determined was used to design the larger scale cooling crystallizations (10 mL and $350 \mathrm{~mL})$.

The Cambridge Reactor Design Polar Bear Plus crystallizer was used for the $10 \mathrm{~mL}$ cooling crystallizations with overhead and magnetic stirring in $20 \mathrm{~mL}$ glass vials. Crystallizations with overhead stirring, implemented using magnetically controlled overhead stirrers from Technobis, were carried out at four different saturation concentrations of succinic acid $\left(\mathrm{T}_{\mathrm{sat}}=20,27,30\right.$ and $\left.40{ }^{\circ} \mathrm{C}\right)$, with four different concentrations of PP123 $(0 \%, 0.17 \%, 0.25 \%$ and $0.5 \%$ of the saturation concentration of succinic acid). The dissolved polymer concentrations used are defined here, and for all other crystallizations in this study, as the percentage of the saturation concentration of succinic acid expressed in $\mathrm{g} / \mathrm{mL}$ of water. These express the very low concentrations of polymer 
used, for example, for $\mathrm{T}_{\mathrm{sat}}=20{ }^{\circ} \mathrm{C}(0.06 \mathrm{~g} / \mathrm{mL}$ of succinic acid $), 0.5 \%$ polymer concentration would be $0.00030 \mathrm{~g} / \mathrm{mL}, 0.25 \%$ would be $0.00015 \mathrm{~g} / \mathrm{mL}$ and $0.17 \%$ would be $0.00010 \mathrm{~g} / \mathrm{mL}$ of polymer; the $\mathrm{T}_{\text {sat }}$ concentrations are taken from the solubility curve in Figure 2. Crystallizations with magnetic stirring at a rate of $325 \mathrm{rpm}$ were carried out under a more limited set of conditions: with no polymer and $0.17 \%$ of polymer for $\mathrm{T}_{\text {sat }}=30^{\circ} \mathrm{C}$. All $10 \mathrm{~mL}$ crystallizations were subject to a linear cooling profile from $10{ }^{\circ} \mathrm{C}$ above the saturation temperature of the given succinic acid concentration to $5{ }^{\circ} \mathrm{C}$ with a cooling rate of $-0.5{ }^{\circ} \mathrm{C} \mathrm{min}^{-1}$. The crystalline product was filtered at the end of the cooling profile and visual analysis was carried out using optical microscopy.

The $350 \mathrm{~mL}$ cooling crystallizations were carried out using a $400 \mathrm{~mL}$ jacketed glass vessel equipped with overhead stirring at $325 \mathrm{rpm}$ (PTFE pitch blade turbine). The set-up is shown in Figure 3. The temperature was controlled using a PT-100 temperature probe connected to a Huber Ministat 230 thermoregulator. A PAT array was used, consisting of an RXN2 Hybrid Raman analyzer with immersion probe and $785 \mathrm{~nm}$ laser (Kaiser with iC Raman 4.1 software), D600L Lansentec Focused Beam Reflectance Measurement (FBRM) probe (equipped with control interface software version 6.7) and a particle vision and measurement (PVM) V819 probe (Mettler Toledo) with an on-line image acquisition software (version 8.3). The pre- and post-processing of the data was done with Matlab R2013, iC Raman 4.1 and Excel. The data from the FBRM and the Huber is transmitted in real-time to the CryPRINS software (Crystallisation Process Informatics System). This allows real-time monitoring of the FBRM counts, ATR-UV/Vis signal and the temperature, as well as setting a temperature profile and performing supersaturation control.

Different saturation concentrations of succinic acid $\left(\mathrm{T}_{\text {sat }}=20,27,30,32,34,37\right.$ and $\left.40{ }^{\circ} \mathrm{C}\right)$ in the presence of different concentrations of $\mathrm{PP} 123(0 \%, 0.17 \%, 0.25 \%$ and $0.5 \%$ of the saturation concentration of succinic acid) were used. From each crystallization a $6 \mathrm{~mL}$ sample was also taken 
for off-line analysis (PXRD, Raman and SEM imaging). All crystallizations were subject to a linear cooling profile from $10{ }^{\circ} \mathrm{C}$ above the saturation temperature of the given succinic acid concentration to $5{ }^{\circ} \mathrm{C}$ with a cooling rate of $-0.5^{\circ} \mathrm{C} \mathrm{min}^{-1}$. The MSZW was determined at this 350 $\mathrm{mL}$ scale from the in situ FBRM data.

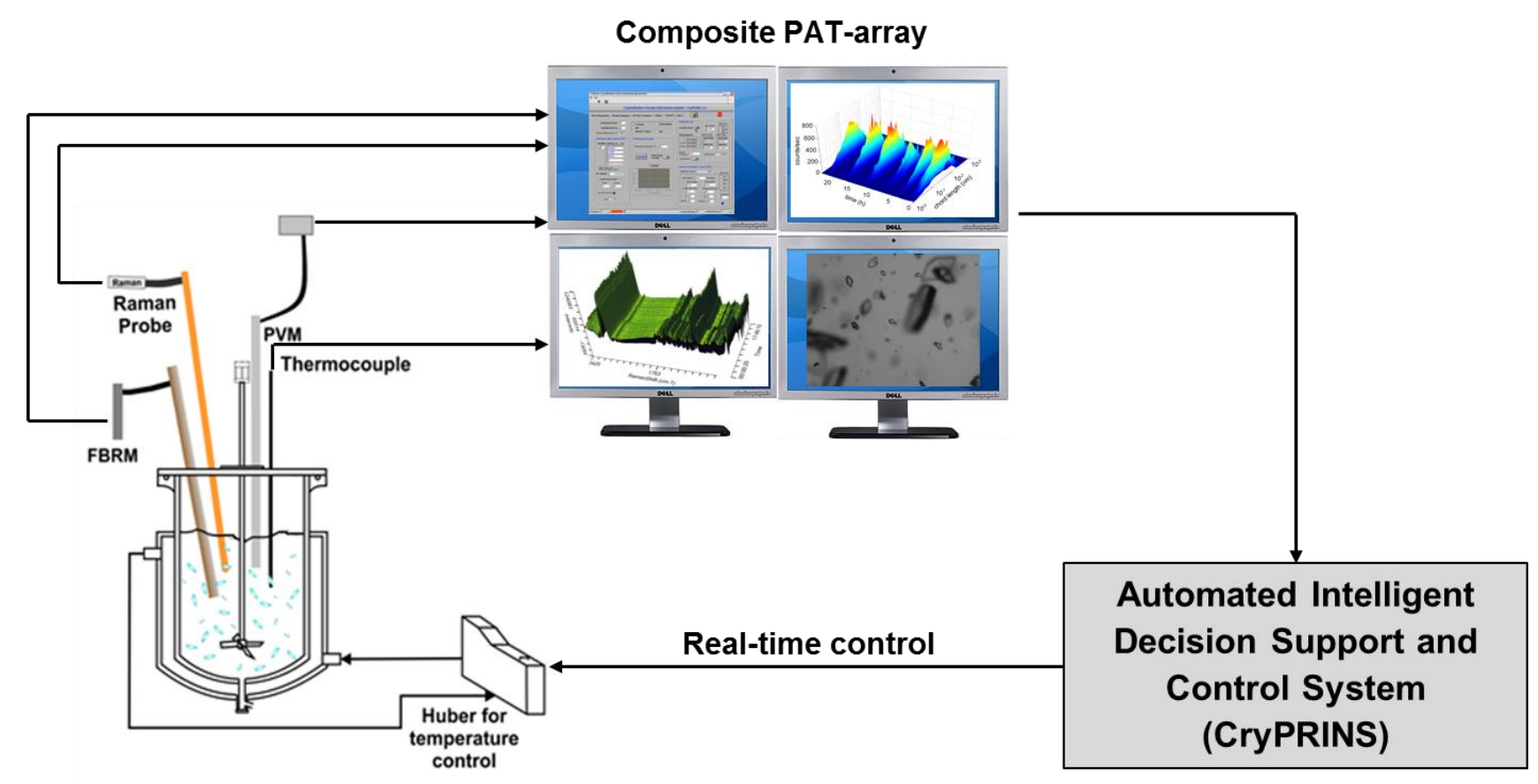

Figure 3. Experimental set up for $350 \mathrm{~mL}$ crystallizations.

Additional crystallizations of succinic acid at $10 \mathrm{~mL}$ scale with overhead stirring were performed using Pluronic F127 (PF127) as well as the separate blocks of Pluronic P123: PEG1000 and PPG4000 as additives. Crystallizations in the presence of PF127 were carried out for succinic acid concentration $\mathrm{T}_{\text {sat }}=30{ }^{\circ} \mathrm{C}$ using $0.17 \%$ and $0.5 \%$ of polymer. Crystallizations carried out in the presence of PEG1000 were implemented for succinic acid concentrations $\mathrm{T}_{\text {sat }}=30{ }^{\circ} \mathrm{C}$ and $40{ }^{\circ} \mathrm{C}$ using $0.5 \%$ and $1 \%$ of polymer. Crystallizations carried out in the presence of PPG4000 were implemented for succinic acid saturation concentrations $\mathrm{T}_{\text {sat }}=20,27,30$ and 40 
${ }^{\circ} \mathrm{C}$ using $0.17 \%, 0.25 \%$ and $0.5 \%$ of polymer. The same cooling profile was used as for the previous $10 \mathrm{~mL}$ crystallizations.

For the washing and recrystallization experiments, crystals of a sample from a $350 \mathrm{~mL}$ scale experiment $\left(\mathrm{T}_{\text {sat }}=50{ }^{\circ} \mathrm{C} ; 0.5 \% \mathrm{PP} 123\right)$ were recrystallized from water at $10 \mathrm{~mL}$ scale for succinic acid concentration $\mathrm{T}_{\text {sat }}=30{ }^{\circ} \mathrm{C}$ using overhead stirring. A second sample was washed, in combination with filtration, with deionized water at $4{ }^{\circ} \mathrm{C}$ and then recrystallized after drying. This procedure was repeated with other crystals from the same sample but using diethyl ether as the washing solvent. Additionally, $1.5 \mathrm{~g}$ of crystals from the original morphology-modified sample were slurried in $10 \mathrm{~mL}$ of diethyl ether for one hour and the dry product was recrystallized from water for succinic acid concentration $\mathrm{T}_{\text {sat }}=30{ }^{\circ} \mathrm{C}$. The same cooling profile was used as for the previous $10 \mathrm{~mL}$ crystallizations.

Off-line characterization methods were also used to complement the PAT. Raman spectra and images of the crystals were obtained using a Thermo Scientific DXR Raman microscope (laser at $780 \mathrm{~nm}$ and OMNIC software version 8). All images were taken at $4 \mathrm{x}$ magnification. Images of $10 \mathrm{~mL}$ scale crystallizations were taken using a Leica DM1000 microscope equipped with an Infinity 2 microscopy camera at 4x magnification. Scanning Electron Microscopy (SEM) images were obtained using a JEOL SEM6480LV SEM in which samples were coated with gold using an Edward Sputter Coater S15OB.

Face indexing was carried out using a Rigaku Oxford Diffraction (formerly Agilent Technologies) Xcalibur diffractometer with Mo-K $\alpha(\lambda=0.71073 \AA)$ radiation. Unit cell screenings were carried out at $150 \mathrm{~K}$ where the temperature was controlled using an Oxford Cryosystems Cryostream. Face indexing was then carried out using the CrysAlisPro 171.37.33 software. 
Analysis of the crystal structure and morphology of $\beta$-succinic acid was carried out using Mercury $3.5^{51}$.

Powder X-ray Diffraction data were collected in flat-plate mode using a Bruker D8 Advance diffractometer equipped with monochromatic $\mathrm{Cu}-\mathrm{K} \alpha$ radiation $(\lambda=1.54056 \AA)$ in reflection geometry at $298 \mathrm{~K}$. The purity of the samples was examined using Differential Scanning Calorimetry (DSC), Nuclear Magnetic Resonance (NMR) and Fourier Transform infra-red (FTIR) spectroscopy in order to confirm that the polymer did not remain in the product (see ESI, Figures SI04-06). DSC studies were performed using a Thermal Advantage Q20 DSC from TA Instruments, equipped with Thermal Advantage Cooling System 90 and operated with a dry nitrogen purge gas at a flow rate of $18 \mathrm{~cm}^{3} \mathrm{~min}^{-1} \cdot 2-4 \mathrm{mg}$ samples were placed in sealed Tzero aluminum pans and a heating rate of $2.5 \mathrm{~K} \mathrm{~min}^{-1}$ was used. Analysis of the data was carried out using TA Universal Analysis software. An Agilent Technologies $500 \mathrm{MHz}{ }^{1} \mathrm{H}-\mathrm{NMR}$ instrument was used for NMR studies. Samples were dissolved in deuterated water. The FTIR spectra were recorded using a Perkin Elmer FTIR Spectrometer in the range $4000-500 \mathrm{~cm}^{-1}$ with an ATR sampling accessory at room temperature.

\section{RESULTS AND DISCUSSION}

\section{Metastable zone width at 3 and $350 \mathrm{~mL}$ scales}

Metastable zone width measurements with and without PP123 present were carried out at two scales: $3 \mathrm{~mL}$ with magnetic stirring and $350 \mathrm{~mL}$ with overhead stirring. Figure $4 \mathrm{a}$ shows the MSZW at $3 \mathrm{~mL}$ scale with no polymer and with $0.5 \%$ of polymer in solution: the addition of PP123 generates a shift of the MSZW of around $7-10{ }^{\circ} \mathrm{C}$ at this scale. It should be noted that these

measurements were performed at $3 \mathrm{~mL}$ scale and findings by Kadam et $a l^{52}$ have shown significant variation in the nucleation temperature at small scale; repeat determinations would be essential to 
establish if this temperature shift is statistically significant. The MSZW at $350 \mathrm{~mL}$ is shown in Figure $4 \mathrm{~b}$. At a larger scale the addition of PP123 at several concentrations $(0.17 \%, 0.25 \%$ and $0.5 \%$ ) does not significantly change the nucleation temperature. In Figure 4c the two MSZW in the absence of polymer, at $3 \mathrm{~mL}$ and $350 \mathrm{~mL}$, are shown together. At a temperature higher than $27{ }^{\circ} \mathrm{C}$ the two curves overlap while, at lower temperature, the nucleation temperature at the small scale seems to be higher compared to the larger scale. It should also be noted that the two curves in the present case were measured using two different techniques (turbidity for the $3 \mathrm{~mL}$ experiments and FBRM for the $350 \mathrm{~mL}$ ), therefore a fair comparison between the two sets of data is not possible. 


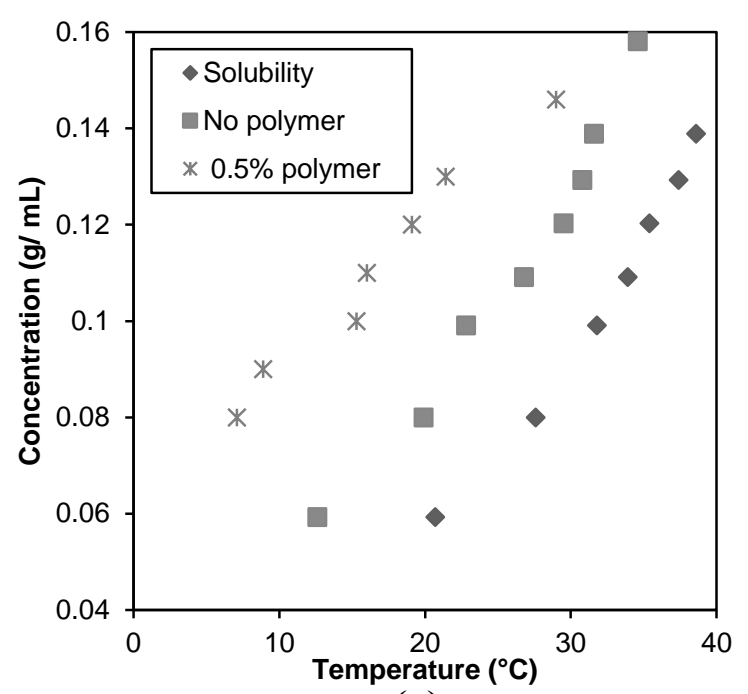

(a)

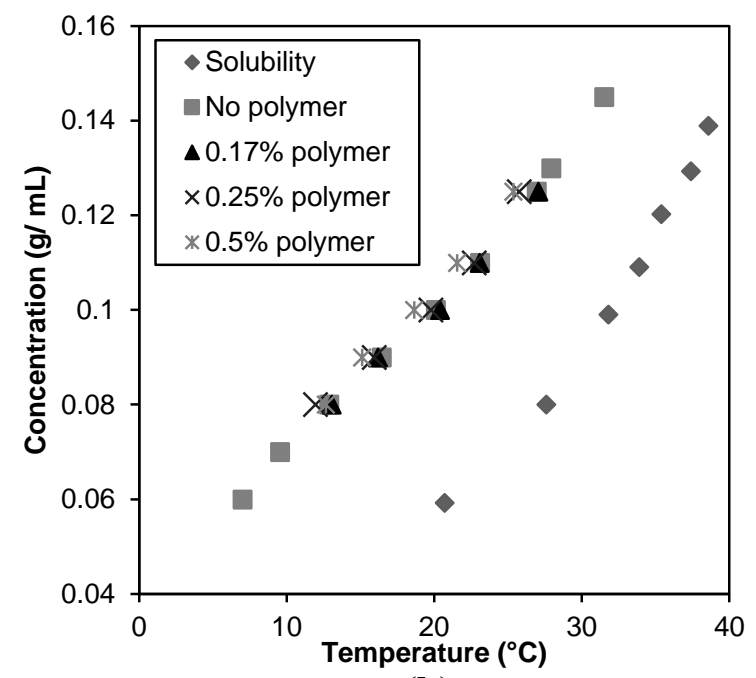

(b)

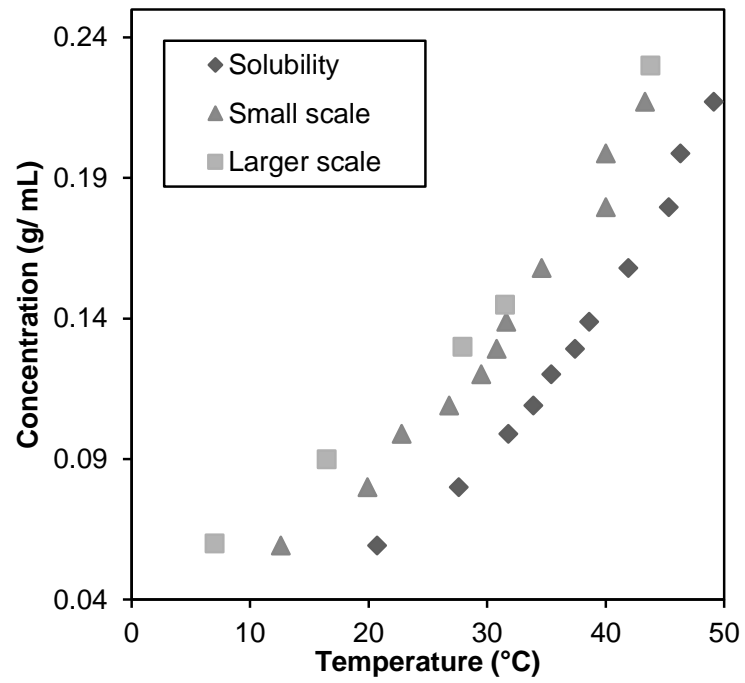

(c) 
Figure 4. Metastable zone width for succinic acid at two different scales, (a) $3 \mathrm{~mL}$ and (b) $350 \mathrm{~mL}$, and different polymer concentrations. (c) comparison between the MSZW at $3 \mathrm{~mL}$ (small scale) and $350 \mathrm{~mL}$ (larger scale) with no polymer present.

\section{Morphology modification using a polymer additive in crystallizations at $3 \mathrm{~mL}$ scale}

In-line imaging was implemented for the duration of the heating and cooling profiles in the Crystalline for measurements at $3 \mathrm{~mL}$ scale (Figure 5). At low saturation $\left(\mathrm{T}_{\text {sat }}=30^{\circ} \mathrm{C}\right)$ the images suggest that there is no change in crystal morphology with $0.5 \%$ PP123 present. However, at higher saturation $\left(\mathrm{T}_{\mathrm{sat}}=40{ }^{\circ} \mathrm{C}\right)$ in the presence of polymer the succinic acid crystals are elongated and needle-like whereas with no polymer present they remain non-uniform plates. As the concentration of succinic acid is increased to $\mathrm{T}_{\mathrm{sat}}=50^{\circ} \mathrm{C}$, the crystals grown in the presence of polymer are more rod-like. It is clear that in the presence of the PP123, the concentration of succinic acid affects the morphology of the resulting crystals whereas with no polymer present the crystal shape is unchanged with increasing succinic acid concentration.

As a result of these observations, a more detailed analysis of the effect of the polymer was carried out at different saturations of succinic acid in the presence of a range of concentrations of polymer at $10 \mathrm{~mL}$ and $350 \mathrm{~mL}$ scale. 

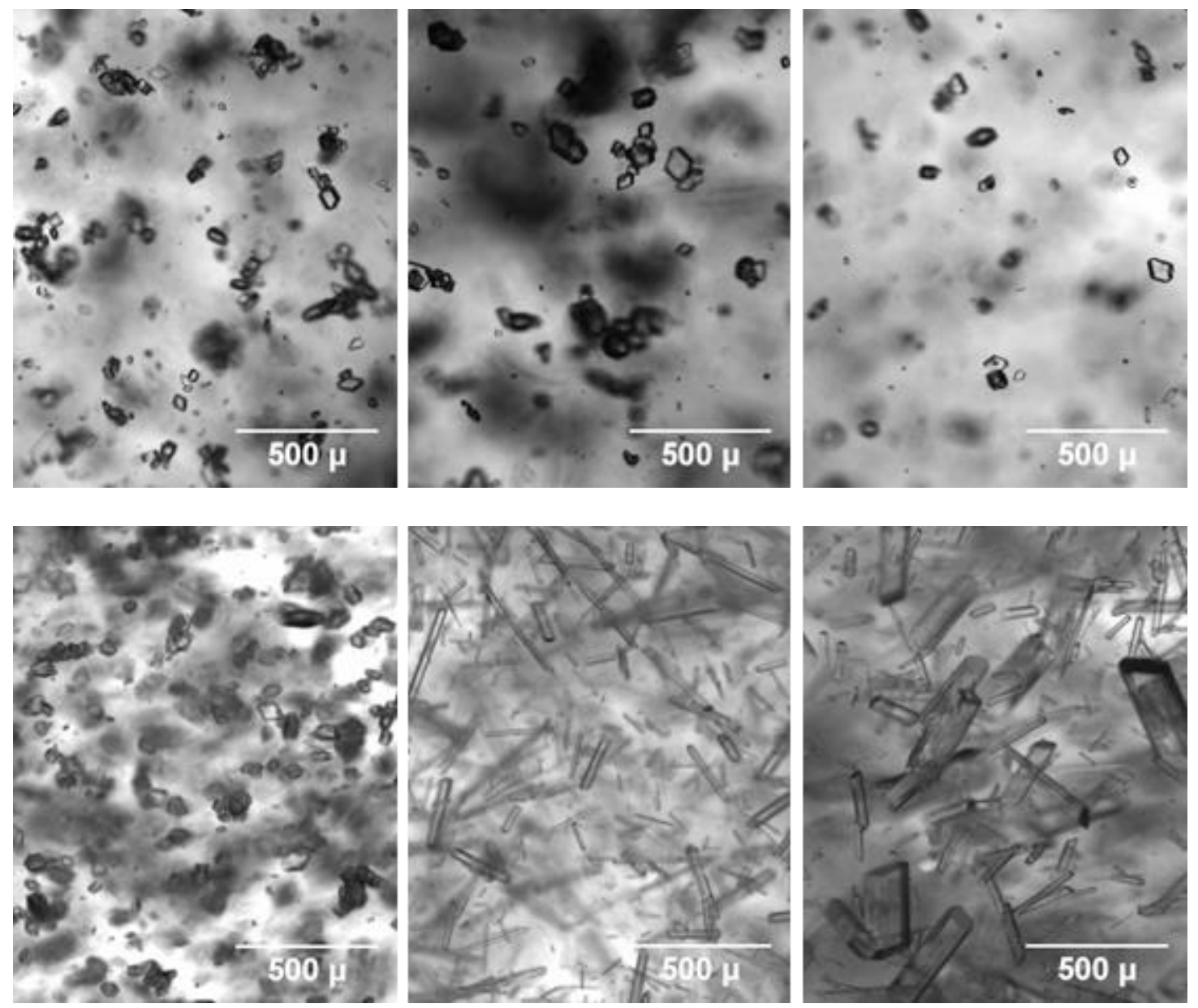

Figure 5. (top) Crystals of succinic acid from $\mathrm{T}_{\text {sat }}=30{ }^{\circ} \mathrm{C}, 40{ }^{\circ} \mathrm{C}$ and $50{ }^{\circ} \mathrm{C}$ with no polymer present; (bottom) Crystals of succinic acid from $\mathrm{T}_{\text {sat }}=30^{\circ} \mathrm{C}, 40{ }^{\circ} \mathrm{C}$ and $50{ }^{\circ} \mathrm{C}$ all with $0.5 \% \mathrm{PP} 123$ present.

\section{Morphology modification using a polymer additive in crystallizations at $10 \mathrm{~mL}$ scale}

Crystallizations at $10 \mathrm{~mL}$ scale with overhead stirring were performed, changing the succinic acid and polymer concentrations. The morphology of the crystals obtained was analyzed using optical microscopy. It is clear that the effect of the polymer is dependent on both the concentration of succinic acid and the concentration of PP123 present. With no PP123 present in solution, succinic acid crystallizes from water in a non-uniform plate-like morphology (as shown in Figure 
6) which correlates with previous reports. ${ }^{53-55}$ At a concentration of $0.5 \%$ PP123 and low concentration of succinic acid $\left(\mathrm{T}_{\text {sat }}=20^{\circ} \mathrm{C}\right)$ block-like crystals are produced, however they are relatively non-uniform as shown in Figure 6. As the concentration of succinic acid is increased to $\mathrm{T}_{\text {sat }}=30{ }^{\circ} \mathrm{C}$, the crystals remain block-like but the side faces appear to have a more irregular surface. Crystallization carried out for $\mathrm{T}_{\text {sat }}=40{ }^{\circ} \mathrm{C}$ at $0.5 \%$ polymer yielded crystals of needle-like morphology. This trend of changing morphology with changing saturation of succinic acid can also be observed at lower concentrations of PP123, however the block-like crystals are accessible at higher saturations with lower concentration of PP123, and significantly improved uniformity in crystal size can be obtained.

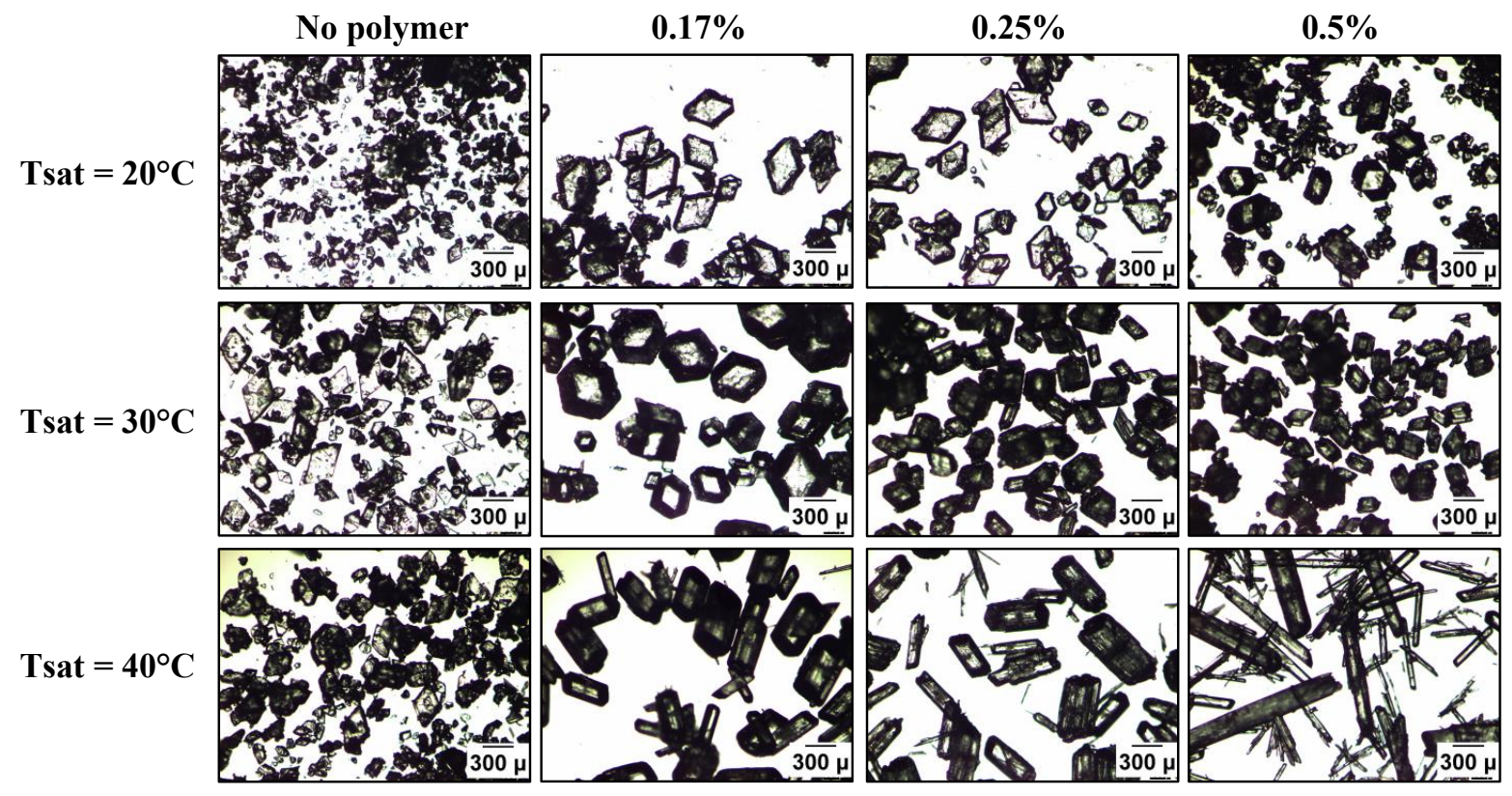

Figure 6. Microscope images of succinic acid crystals from crystallizations carried out at $10 \mathrm{~mL}$ scale. 
Crystallizations carried out at $10 \mathrm{~mL}$ scale using magnetic stirring also showed a morphology change in presence of the PP123 polymer additive (ESI, Figure SI01). However, with this mode of stirring the crystal morphology was very non-uniform both with and without PP123 present. This suggests that the mixing conditions are non-uniform and crystal breakage may be occurring due to the abrasive action of the stirring bar, which does not happen when an overhead impeller is used for mixing. Furthermore, the crystals of favorable block like morphology observed with overhead stirring at low saturation of succinic acid or low PP123 concentration were not observed with magnetic stirring using the same conditions.

\section{Scaling of additive morphology modification to crystallizations at $350 \mathrm{~mL}$ scale}

Crystallizations at different saturation concentrations of succinic acid in aqueous solutions containing different concentrations of PP123 were also carried out at $350 \mathrm{~mL}$ scale and monitored in situ using a range of process analytical technologies (Raman, PVM and FBRM). Images of the crystal morphology from crystallizations carried out at $350 \mathrm{~mL}$ scale are shown in Figure 7. A similar trend in the morphology change at this scale was observed in the $10 \mathrm{~mL}$ batch experiments described in the previous section. The morphology modification induced by the polymer additive is thus scalable.

As seen in the $10 \mathrm{~mL}$ crystallizations with overhead stirring, in the absence of polymer succinic acid crystallizes in non-uniform, diamond shaped plates. At higher saturation of succinic acid the crystals grow larger and more uniform in shape. Upon addition of $0.5 \%$ PP123 at low saturation of succinic acid, crystals grow in a block-like morphology where the crystal faces appear to be growing at equal rates. The shape of these block-like crystals is more uniform compared to those obtained in the $10 \mathrm{~mL}$ experiments using the same concentrations of succinic acid and PP123. At higher saturations and high polymer concentration the shape of the crystals changes to block-like 
to needles. Figure 7 shows crystals obtained for $\mathrm{T}_{\text {sat }}=30{ }^{\circ} \mathrm{C}$ and $0.5 \%$ of polymer in solution: the shape is still block-like but the surface of the crystals appears irregular because of the inhibition effect of the polymer. At higher saturation and the same polymer concentration $(0.5 \%)$ crystals grow as needles.

Again, as observed in the $10 \mathrm{~mL}$ experiments, crystallizations carried out with a lower concentration of PP123 present showed the same trend in morphology change as the saturation of succinic acid is increased. The block-like crystals can once again be accessed at higher saturation with less polymer present. These similarities in crystal morphology at $10 \mathrm{~mL}$ and $350 \mathrm{~mL}$ scale show the morphology modification by the polymer addition to be scalable. Alongside off-line imaging by optical microscopy and SEM, PVM was also used as an in situ monitoring tool to observe the crystal morphology in real time (Figure 8), confirming the ex situ findings.

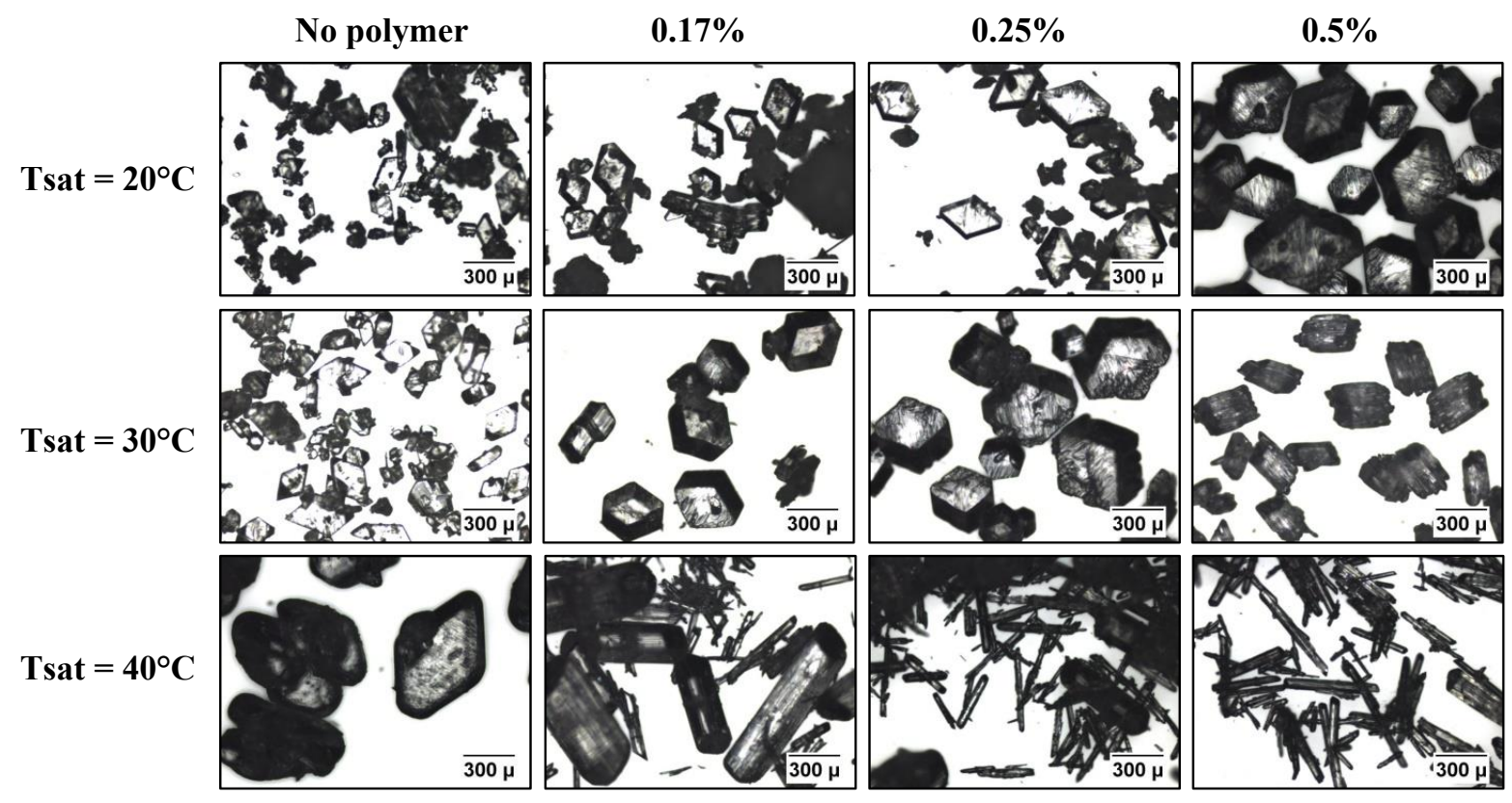

Figure 7. Microscope images of succinic acid crystals from crystallizations carried out at $350 \mathrm{~mL}$ scale. 


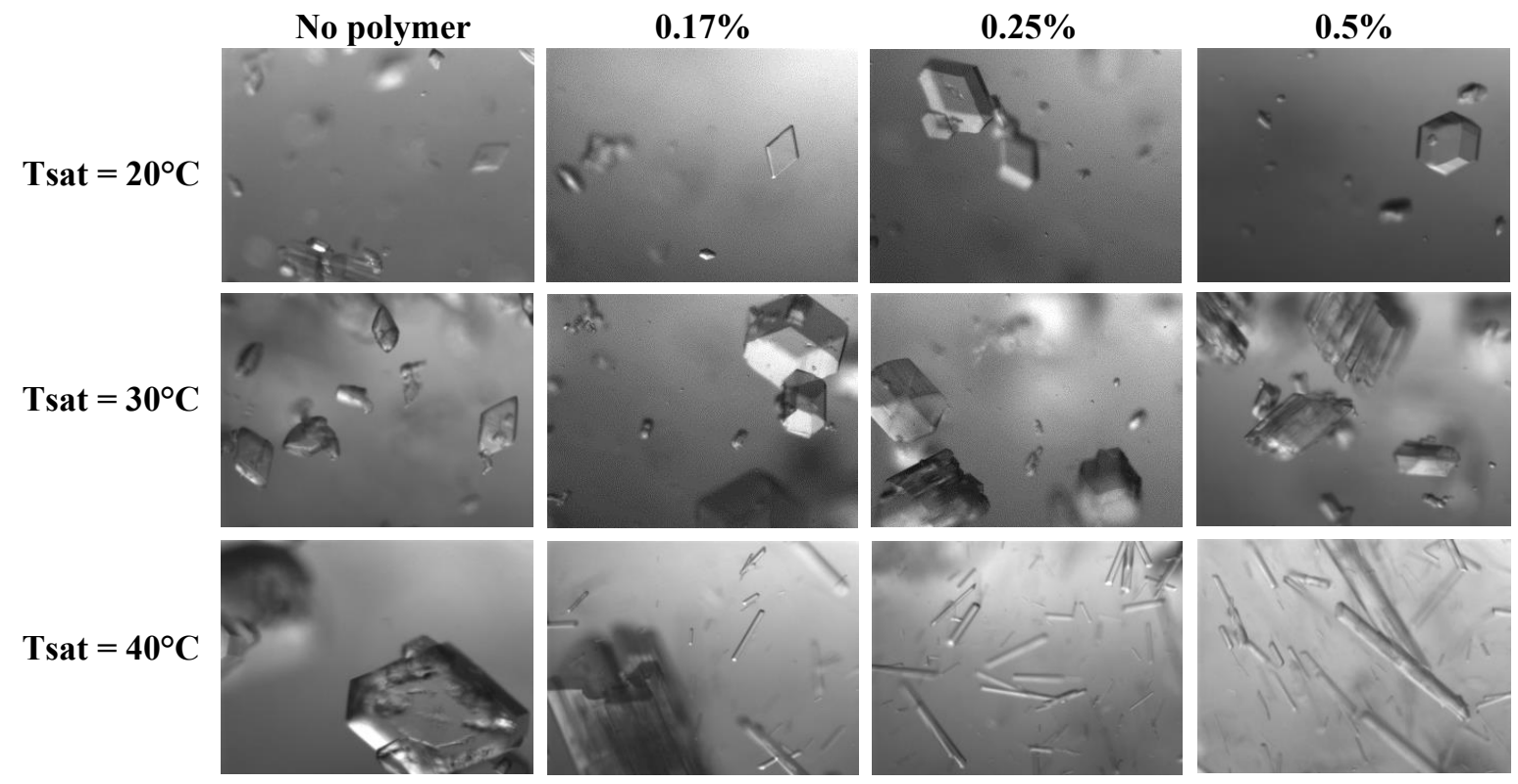

Figure 8. in situ PVM images of succinic acid crystals from the crystallizations carried out at $350 \mathrm{~mL}$ scale.

It is interesting to note that very low concentrations of PP123 can exert a large effect on the crystal morphology and that despite these substantial morphology changes the polymorphic form of succinic acid remained the $\beta$ form in all crystallizations, as confirmed by PXRD and Raman spectroscopy (see ESI, Figures SI02, SI03).

\section{Nature of the morphology change: face indexing}

Face indexing was used to identify the crystal faces involved in the morphology change (Figure 9): the faces identified for the plate-like crystals produced in the presence of no polymer correspond to those previously reported..$^{50,54}$ As discussed in previous literature, ${ }^{55,56}$ in the crystal structure of $\beta$-succinic acid, the (100) face intercepts chains of succinic acid molecules linked by hydrogen bonded carboxylic acid dimers (Figure 10). This makes the (100) face a polar face with 
which water molecules would be likely to interact, inhibiting growth along the direction perpendicular to this face and suggesting why it is the largest face in crystallizations carried out from water.
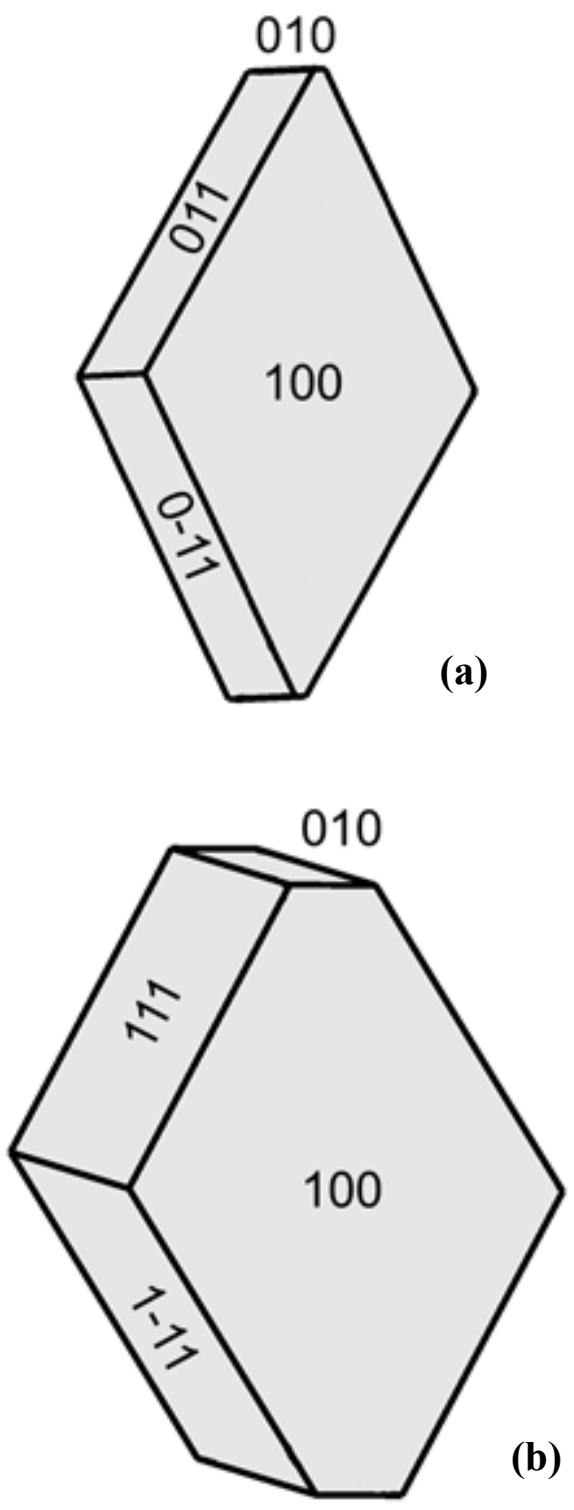


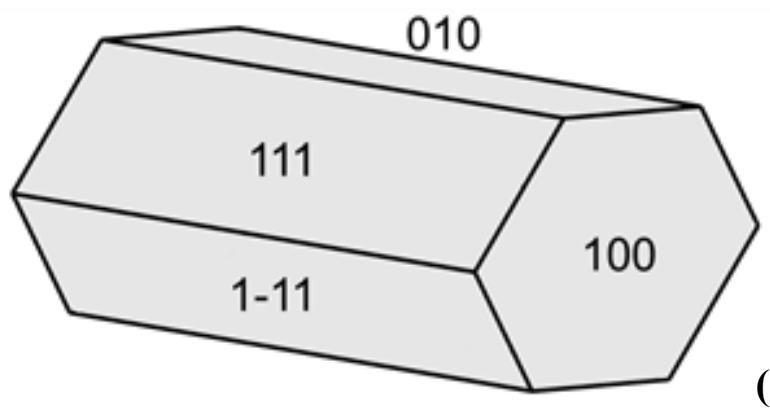

(c)

Figure 9. Faces of succinic acid crystals: (a) plate-like crystals from crystallizations with no polymer; (b) block-like crystals from low saturation crystallizations and (c) rod or needle-like crystals from high saturation crystallizations.

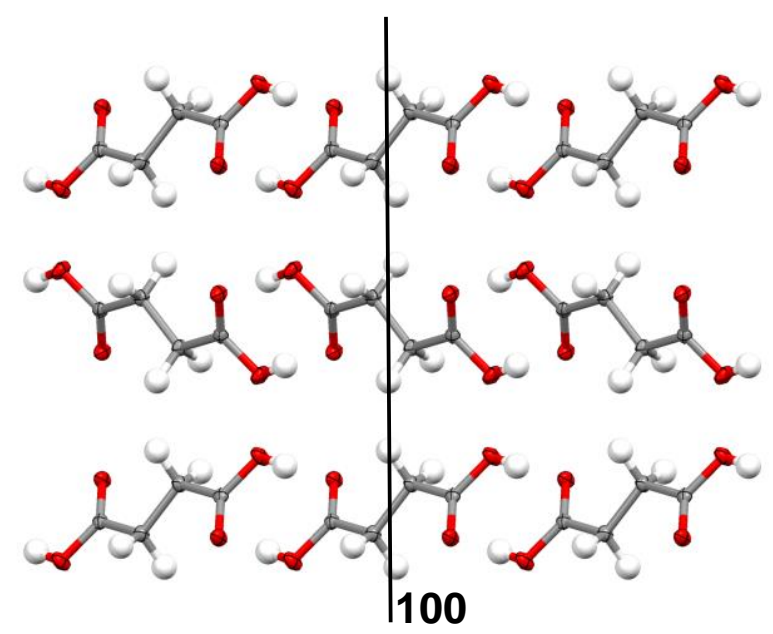

Figure 10. Packing arrangement of $\beta$-succinic acid through the (100) face

It is evident that upon addition of the PP123, the (100) face remains prominent (as shown in Figure 11). However its prominence decreases with increased saturation of succinic acid and concentration of PP123 as the crystal shape moves towards a needle-like morphology. This suggests that the growth rate in the direction of this face (along the crystallographic $a$ axis) is faster than those of the other faces under these conditions, which is also evident in preferred orientation in the PXRD patterns (see ESI, Figure SI02). In the experimental PXRD pattern for crystallizations in the absence of polymer, with prominent (100) face, the (100) peak is larger, whereas in the 
PXRD pattern for the needle-like crystals with a far less prominent (100) face, this peak is effectively not present. The change in crystal shape and observed increase in the growth rate of the (100) face suggests that the growth of the side faces of the crystal is being inhibited by the PP123, slowing down growth in those directions and leading to needle-like growth along the (100) direction.
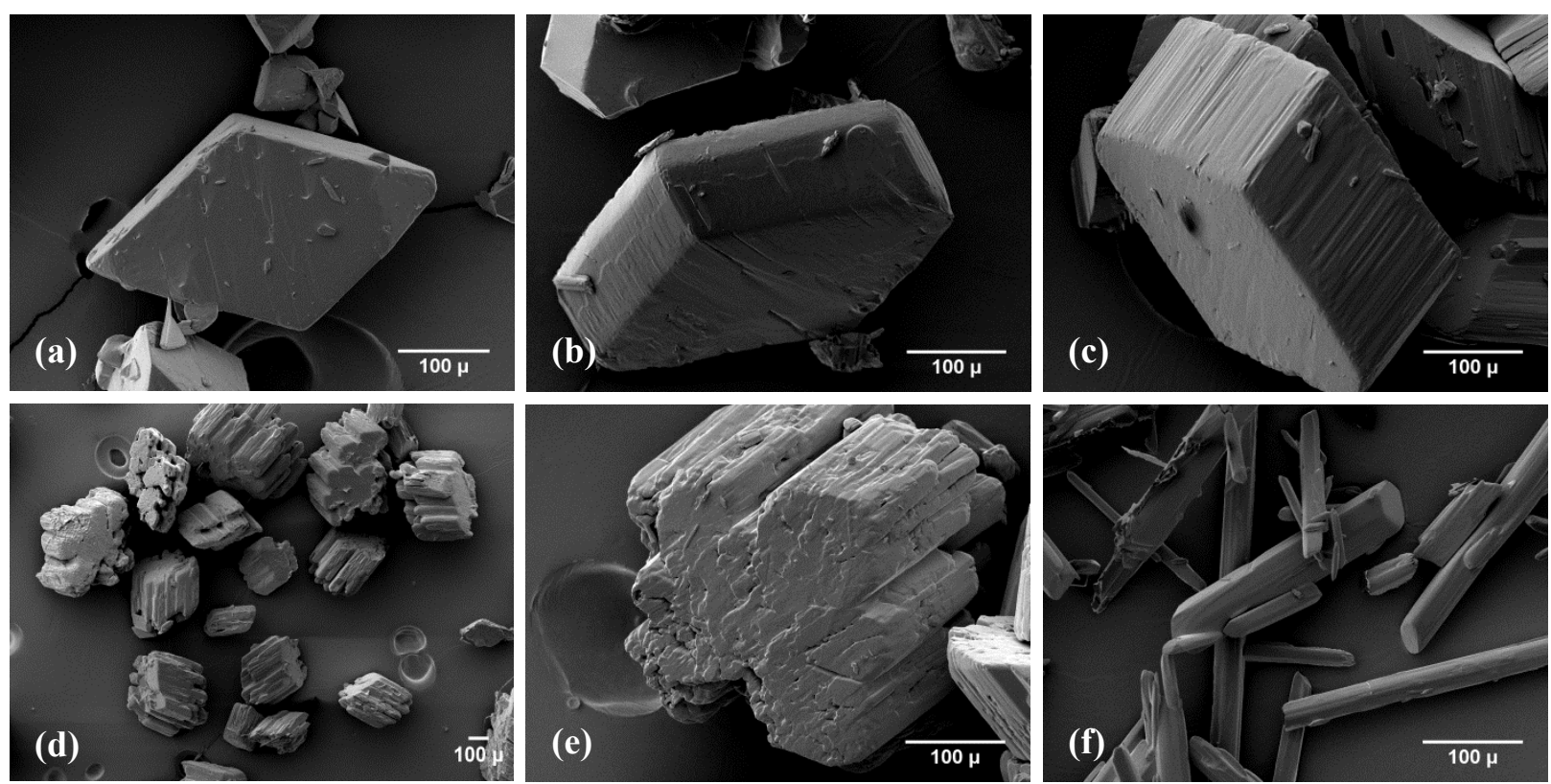

Figure 11. SEM images of succinic acid crystals crystallized under the following conditions: (a) $\mathrm{T}_{\text {sat }}=30{ }^{\circ} \mathrm{C}$, no polymer (b) $\mathrm{T}_{\text {sat }}=20{ }^{\circ} \mathrm{C}, 0.25 \%$ PP 123 (side view) (c) $\mathrm{T}_{\text {sat }}=30{ }^{\circ} \mathrm{C}, 0.17 \%$ PP 123 (d) $\mathrm{T}_{\text {sat }}=30{ }^{\circ} \mathrm{C}, 0.5 \%$ PP123 (e) $\mathrm{T}_{\text {sat }}=27{ }^{\circ} \mathrm{C}, 0.5 \%$ PP123 (f) $\mathrm{T}_{\text {sat }}=40{ }^{\circ} \mathrm{C}, 0.5 \%$ PP123.

In the presence of the PP123, the (111) type faces become more dominant over the (011) face. This face change can initially be observed in crystals obtained from crystallizations at low saturation of succinic acid and low concentration of polymer which retain a plate-like morphology but in which both the (011) and the (111) face are present (Figure 11b). Images obtained from scanning electron microscopy (SEM) show this and that at higher saturation only the (111) and (1- 
11) faces are observed (Figure 11c). This suggests that growth along the (111) and (1-11) directions is being inhibited by the presence of the polymer, thus allowing these to become more prominent faces.

The SEM images also reveal a more detailed picture of the surface of the crystals. On the blocklike crystals the (100) face has a smooth surface, however, the (111), (1-11), (010) and (0-10) faces have a more irregular surface with well-defined steps (Figure 11). These irregularities are more evident in the crystals produced from higher saturation experiments, although it is clear that these remain single crystals; the surface of the (100) face remains smooth and appears too uniform for the crystals to be agglomerates, while the crystals also extinguish polarized light under a microscope. The diffraction pattern of such crystals generally shows single, sharp spots characteristic of single crystals, but with some diffuse streaky spots evident.

\section{Polymer-surface interactions}

In order to understand which part of the PP123 may be interacting with the growing succinic acid crystals and exerting the morphology modification effect, cooling crystallizations were carried out at $10 \mathrm{~mL}$ scale using the separate blocks of Pluronic P123 (PPG4000 and PEG1000) as additives (Figure 12). It was found that there was no effect on the morphology of succinic acid in the presence of the hydrophilic block, PEG1000, even when the concentration of polymer was increased to $1 \%$. The crystallizations with PPG4000, in contrast, produced mostly the morphologymodified block-like crystals, with the same faces as the crystals produced from experiments at low saturation of succinic acid or low concentration of PP123, as confirmed by visual analysis and face indexing. This suggests that it is the hydrophobic PPG4000 block of the block co-polymer, PP123 that is interacting with the growing crystal and modifying the morphology. 

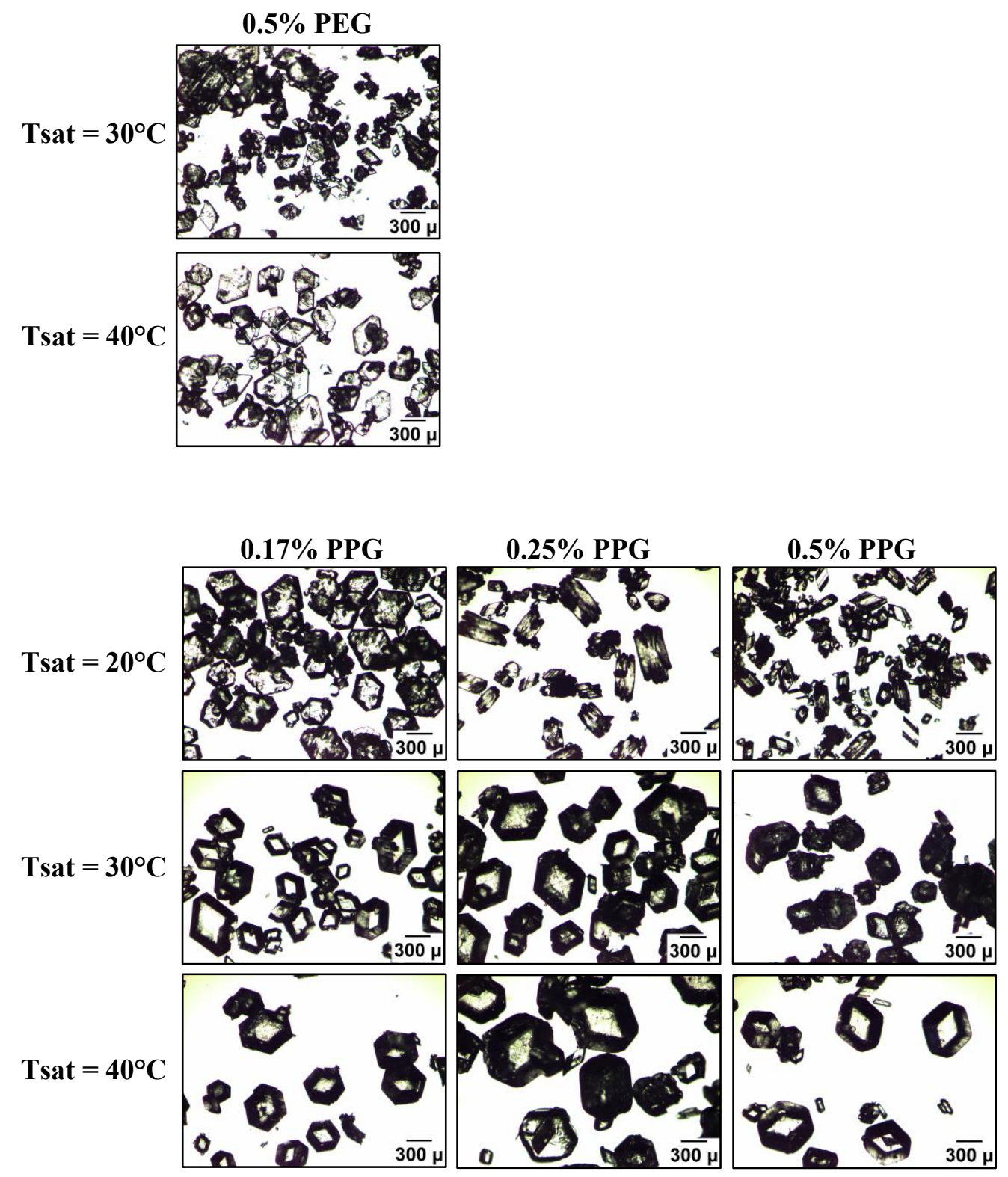

Figure 12. Microscope images of succinic acid crystals from crystallizations carried out with (top) PEG1000 and (bottom) PPG4000, at $10 \mathrm{~mL}$ scale.

Use of PPG4000 alone as an additive appears to have some additional benefits. In contrast to the experiments with PP123, at high saturation of succinic acid the crystals produced in the presence 
of PPG4000 are still block-like rather than needle-like (Figure 12, bottom right), extending the concentration range over which this favorable morphology is obtained.

Crystallization in the presence of Pluronic F127 (PF127) was also carried out at $10 \mathrm{~mL}$ scale. PF127 has a shorter PPG and longer PEG block than PP123. As observed with the PEG1000, PF127 had no effect on crystal morphology, indicating again that the PPG block is important in the morphology change.

\section{Molecular-level interactions}

Hydrogen bonded chains of succinic acid molecules lie in two orientations in the crystal structure of $\beta$-succinic acid, forming consecutive layers. One orientation of succinic acid chains runs parallel to the (111) plane and the other runs parallel to the (1-11) plane (Figure 13b). The only intermolecular interactions in this direction are short contact interactions between the layers of succinic acid molecules. The hydrophobic $\mathrm{CH}_{2}$ groups lie on the surface of both the (111) and the (1-11) faces, and one possible mechanism for the polymer-additive effect is that these groups may be interacting with the hydrophobic PPG block of the PP123 polymer, causing inhibition of growth on these faces.

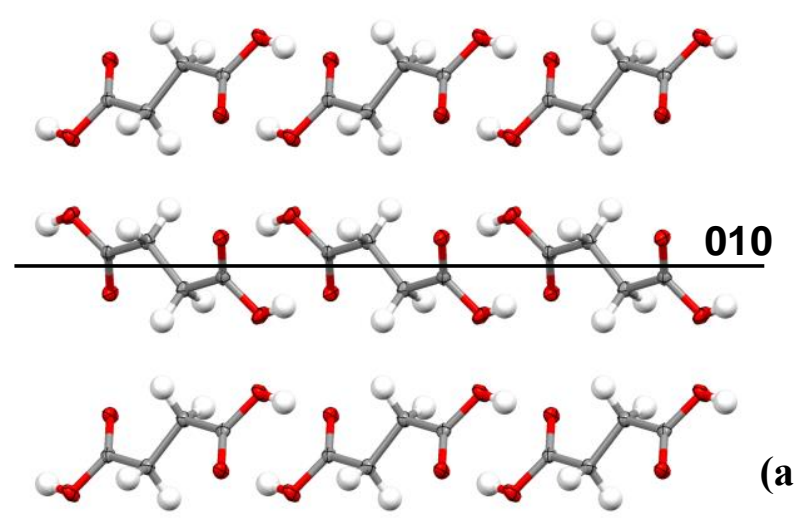




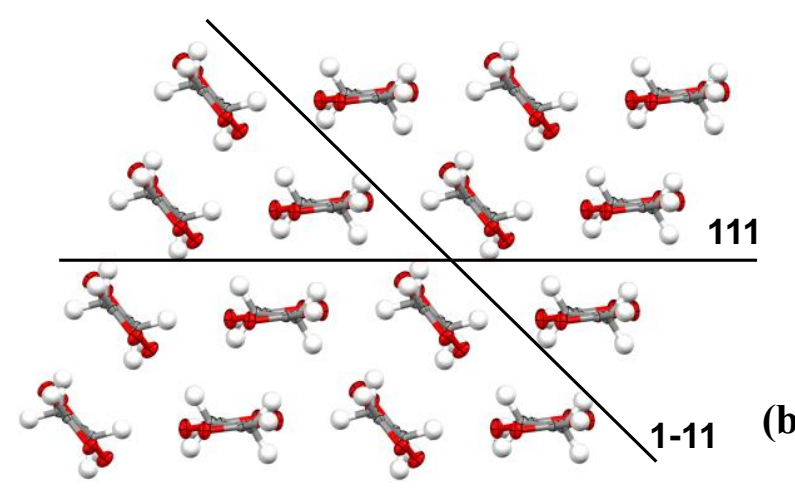

Figure 13. Packing arrangement of $\beta$-succinic acid (a) view down the (010) plane and (b) view down the (111) and (1-11) planes.

\section{Recrystallization and slurrying experiments}

A series of control crystallization experiments were carried out on a sample that had previously been crystallized from solution containing the highest concentration of PP123 additive (and whose morphology had been modified to rod-like) to assess whether trace amounts of PP123 were present in the crystals or on their surfaces.

Recrystallization of this sample from water produced crystals of block-like morphology (Figure 14b), indicating that PP123 may remain on the surface of the crystals, in quantities smaller than those detectable by the analytical techniques implemented (SI03-06). Recrystallization of samples that had been repeatedly washed with cold water, in combination with filtration, again continued to produce the morphology-modified crystals. Washing with water also resulted in a significant decrease in crystal yield due to dissolution. This suggests that a small quantity of the polymer still remains bound to the crystal surfaces of the succinic acid following dissolution or washing in a polar solvent. When this method was repeated with a less polar solvent (diethyl ether), the resulting crystals were less block-like however, slurrying of the crystals in diethyl ether for one hour prior to recrystallization from water was found to be a more successful washing technique than washing 
with filtration. The resulting crystals were of plate-like morphology as previously observed in the crystallizations of succinic acid with no polymer present (Figure 6). Thus the non-polar solvent had the effect of removing the polymer from the crystal surfaces, suggesting it is acting as a competitor for the polymer-crystal surface hydrophobic binding interaction. This also supports the conclusion that PP123 is not incorporated in the crystals of succinic acid in exerting its morphology modifying influence.

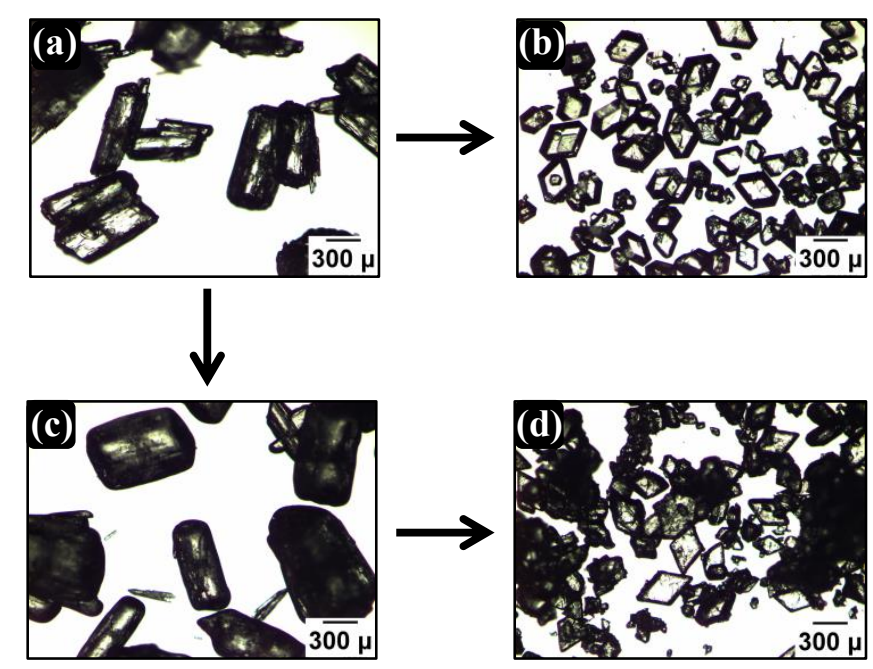

Figure 14. Microscope images of succinic acid crystals produced (a) in the presence of $0.5 \%$ PP123 at $\mathrm{T}_{\text {sat }}=50{ }^{\circ} \mathrm{C}$ ), (b) from subsequent recrystallization from water, (c) after slurrying in diethyl ether and (d) from recrystallization from water after slurrying.

\section{CONCLUSIONS}

The presence of small quantities of the triblock co-polymer Pluronic P123 dissolved in solution is shown to be effective in modifying the crystal morphology of succinic acid when crystallized from water. The effect of the polymer is dependent on both the concentration of succinic acid (explored in this work by carrying out experiments at different saturation temperatures) as well as the concentration of PP123 in solution. 
The modification of crystal morphology induced by the polymer additive is shown to be scalable from $3 \mathrm{~mL}$ up to $350 \mathrm{~mL}$ scale with overhead stirring. The chosen method of mixing was found to be crucial in terms of the crystal morphology and uniformity. Further experiments using the individual blocks of the triblock co-polymer have shown that it is likely that it is the PPG block of the polymer that interacts at the interface, via hydrophobic interactions. The faces being inhibited are hydrophobic faces which are likely to interact with the PPG block of the triblock co-polymer.

The additive-mediated morphology of succinic acid changes from plate-like to the more favorable block-like crystals over a range of succinic acid and PP123 concentrations, offering a convenient route to achieving this improved particle shape, together with initial indications of more consistent particle size. This concentration range can be extended when using only the hydrophobic PPG block of the PP123 as the additive.

\section{Corresponding Author}

C.C.Wilson@bath.ac.uk

\section{ACKNOWLEDGEMENTS}

This work is funded through EPSRC grants EP/I033459/1 (CMAC Centre; CCW \& ZKN) and EP/K503289/1 (Doctoral Training Centre in Continuous Manufacturing and Crystallisation; ARK). ES \& ZKN acknowledge European Research Council grant no. [280106-CrySys] for financial support. Professor Karen Edler is thanked for discussion and advice on the polymers used. The authors also thank the CMAC laboratory at the University of Strathclyde for support and use of the Technobis Crystalline instrument for solubility measurements. 


\section{REFERENCES}

(1) Davey, R. J.; Garside, J. In From Molecules to Crystallizers. An Introduction to Crystallisation, Oxford University Press Inc: New York, United States, 2000; Chapter 5, pp 36.

(2) Wood, W. M. L. Powder Technol. 2001, 121, 53-59.

(3) Kubota, N. Cryst. Res. Technol. 2001, 8, 749-769.

(4) Kubota, N.; Yokota, M.; Mullin, J.W. J. Cryst. Growth 2000, 212, 480-488.

(5) Kubota, N.; Yokota, M.; Mullin, J.W. J. Cryst. Growth 1997, 182, 86-94.

(6) Kubota, N.; Mullin, J.W. J. Cryst. Growth 1995, 152, 203-208.

(7) Kestur, U.S.; Taylor, L.S. Cryst. Growth Des. 2013, 13, 4349-4354.

(8) van Enckevort, W.J.P.; van der Berg, A.C.J.F.; Kreuwel, K.B.G.; Derksen, A.J. J. Crys. Growth 1996, 166, 156-161.

(9) Fevotte, F.; Fevotte, G. Chem. Eng. Sci. 2010, 65, 3191-3198.

(10) Borsos, A.; Majumder, A.; Nagy, Z.K. Comput. Aided Chem. Eng. 2014, 33, 781-786.

(11) Borsos, A.; Majumder, A.; Nagy, Z.K. Cryst. Growth Des. 2015, 16, 555-568.

(12) Poornachary, S.K.; Chow, P.S.; Tan, R.B.H. Adv. Powder Technol. 2008a, 19, 459-473.

(13) Poornachary, S.K.; Chow, P.S.; Tan, R.B.H. J. Cryst. Growth 2008b, 310, 3034-3041.

(14) Majumder, A.; Nagy, Z.K. Chem. Eng. Sci. 2013, 101, 593-602.

(15) Poornachary, S.K.; Chow, P.S.; Tan, R.B.H. Cryst. Growth Des. 2008c, 8, 179-185. 
(16) Clydesdale, G.; Roberts, K.J.; Docherty, R. J. Cryst. Growth 1994, 135, 331-340.

(17) Reis, N. M.; Liu, Z.K.; Reis, C.M.; Mackley, M.R. Cryst. Growth Des. 2014, 14, 31913198.

(18) Saleemi, A.N.; Onyemelukwe, I.I.; Nagy, Z.K. Front. Chem. Sci. Eng. 2013, 7, 79-87.

(19) Hendriksen, B.A.; Grant, D.J.W.; Meenan, P.; Green, D.A. J. Cryst. Growth 1998, 183, $629-640$.

(20) Garnier, S.; Petit, S.; Coquerel, G. J. Cryst. Growth 2002, 234, 207-219.

(21) Price, C.P.; Grzesiak, A.L.; Matzger, A.J. J. Am. Chem. Soc. 2005, 127, 5512-5517.

(22) Weissbuch, I.; Popovitz-Biro, R.; Lahav, M.; Leiserowitz, L. Acta Crystallogr. Sect. B: Struct. Sci. 1995, B51, 115-148.

(23) Gu, G.H.; Chatterjee, K.; Young, V.J.; Grant, D.J.W. J. Cryst. Growth 2002, 235, 471-481.

(24) He, X.; Stowell, J.G.; Morris, K.R.; Pfeiffer, R.R.; Li, H.; Stahly, G.P.; Byrn, S.R. Cryst. Growth Des. 2001, 1, 305-312.

(25) Mo, Y.; Dang, L.; Wei, H. Ind. Eng. Chem. Res. 2011, 50, 10385-10392.

(26) Mukuta, T.; Lee, A.Y.; Kawakami, T.; Myerson, A.S. Cryst. Growth Des. 2005a, 5, 14291436.

(27) Mukuta, T.; Lee, A.Y.; Kawakami, T.; Myerson, A.S. Cryst. Growth Des. 2005b, 5, 14291436.

(28) Tian, F.; Baldursdottir, S.; Rantanen, J. Mol. Pharm. 2009, 6, 202-210. 
(29) Davey, R. J.; Blagden, N.; Righini, S.; Alison, H.; Ferrari, S.E. J. Phys. Chem. 2002, 106, 1954-1959.

(30) Weissbuch, I.; Lahav, M.; Leiserowitz, L. Cryst. Growth Des. 2003, 3, 125-150

(31) Berkovitch-Yellin, Z.; van Mil, J.; Addadi, L.; Idelson, M.; Lahav, M.; Leiserowitz, L. J. Am. Chem. Soc. 1985, 107, 3111-3122

(32) Vaida, M.; Shimon, L.J.W.; Weisenger-Lewin, Y.; Frolow, F.; Lahav, M.; Leiserowitz, L.; McMullan, R.K. Science 1988, 241, 1475-1479

(33) Davey, R.; Fila. W.; Garside, J. J. Cryst. Growth 1986, 79, 607-613.

(34) Berkovitch-Yellin, Z.; Addadi, L.; Idelson, M.; Lahav, M.; Leiserowitz, L. Angew. Chem. Int. Ed. 1982, 21, 1336-1345.

(35) Simone, E.; Steele, G.; Nagy, Z. K. CrystEngComm 2015, 17, 9370-9379.

(36) Xie, S.; Poornachary, S. K.; Chow, P. S.; Tan, R. B. H. Cryst. Growth Des. 2010, 10, $3363-$ 3371.

(37) Vetter, T.; Mazzotti, M.; Brozio, J. Cryst. Growth Des. 2011, 11, 3813-3821.

(38) Alonzo, D. E.; Raina, S.; Zhou, D.; Gao, Y.; Zhang, G.G.Z.; Taylor, L.S. Cryst. Growth Des. 2012, 12, 1538-1547.

(39) Oucherif, K.A.; Raina, S.; Taylor, L.S.; Litster, J.D. CrystEngComm 2013, 15, 2197-2205.

(40) Trasi, N.S.; Taylor, L.S. Cryst. Growth Des. 2012, 12, 3221-3230. 
(41) Ilevbare, G.A.; Liu, H.; Edgar, K.J.; Taylor, L.S. Cryst. Growth Des. 2012a, 12, 60506060.

(42) Ilevbare, G.A.; Liu, H.; Edgar, K.J.; Taylor, L.S. Cryst. Growth Des. 2012b, 12, 31333143.

(43) López-Mejías, V.; Kampf, J. W.; Matzger, A. J. J. Am. Chem. Soc. 2009, 131, 4554-4555.

(44) Thomas, L. H.; Wales, C.; Zhao, L.; Wilson, C. C. Cryst. Growth Des. 2011, 11, 14501452.

(45) Agnew, L. R.; Cruickshank, D, L.; McGlone, T.; Wilson, C. C.; Chem. Commun. 2016, DOI: 10.1039/C6CC01032F.

(46) US Food and Drug Administration SCOGS, http://www.fda.gov/Food/IngredientsPackagingLabeling/GRAS/SCOGS/ucm261458.htm

(47) Rieck, G. D. Recueil des Travaux Chimiques des Pays-Bas 1944, 63, 170-180.

(48) Yu, Q.; Dang, L.; Black, S.; Wei, H. J. Cryst. Growth 2012, 340, 209-215.

(49) Davey, R. J.; Mullin, J. W.; Whiting, M. J. L. J. Cryst. Growth 1982, 58, 304-312.

(50) van der Voort, E. J.Cryst. Growth 1991, 110, 662-668.

(51) Macrae, C. F.; Bruno, I. J.; Chisholm, J. A.; Edgington, P. R.; McCabe, P.; Pidcock, E.; Rodriguez-Monge, L.; Taylor, R.; Van De Streek, J.; Wood, P. A. J. Appl. Cryst., 2008, 41, 466470.

(52) Kaddam, S. S.; Kramer, H. J. M.; ter Horst, J. H. Cryst. Growth Des. 2011, 11, 1271-1277. 
(53) Zhang, Y.; Doherty, M. F. AIChE J. 2004, 50, 2101-2112.

(54) Snyder, R. C.; Veesler, S.; Doherty, M. F. Cryst. Growth Des. 2008, 8, 1100-1101.

(55) Acquah, C.; Cagnetta, M.; Achenie, L. E. K.; Suib, S. L.; Karunanithi, A. Ind. Eng. Chem. Res., 2015, 54, 12108-12113.

(56) Berkovitch-Yellin, Z. J. Am. Chem. Soc. 1985, 107, 8239-8253. 


\section{FOR TABLE OF CONTENTS USE ONLY}

Addition of small quantities of the triblock co-polymer, Pluronic P123 is found to affect the growth of succinic acid crystals from aqueous solutions, at $10 \mathrm{~mL}$ and $350 \mathrm{~mL}$ scale. The crystal morphology can be modified from plate-like to block-like, in a fully reproducible manner. A possible mechanism is proposed for the interaction of the polymer with the crystal surface.

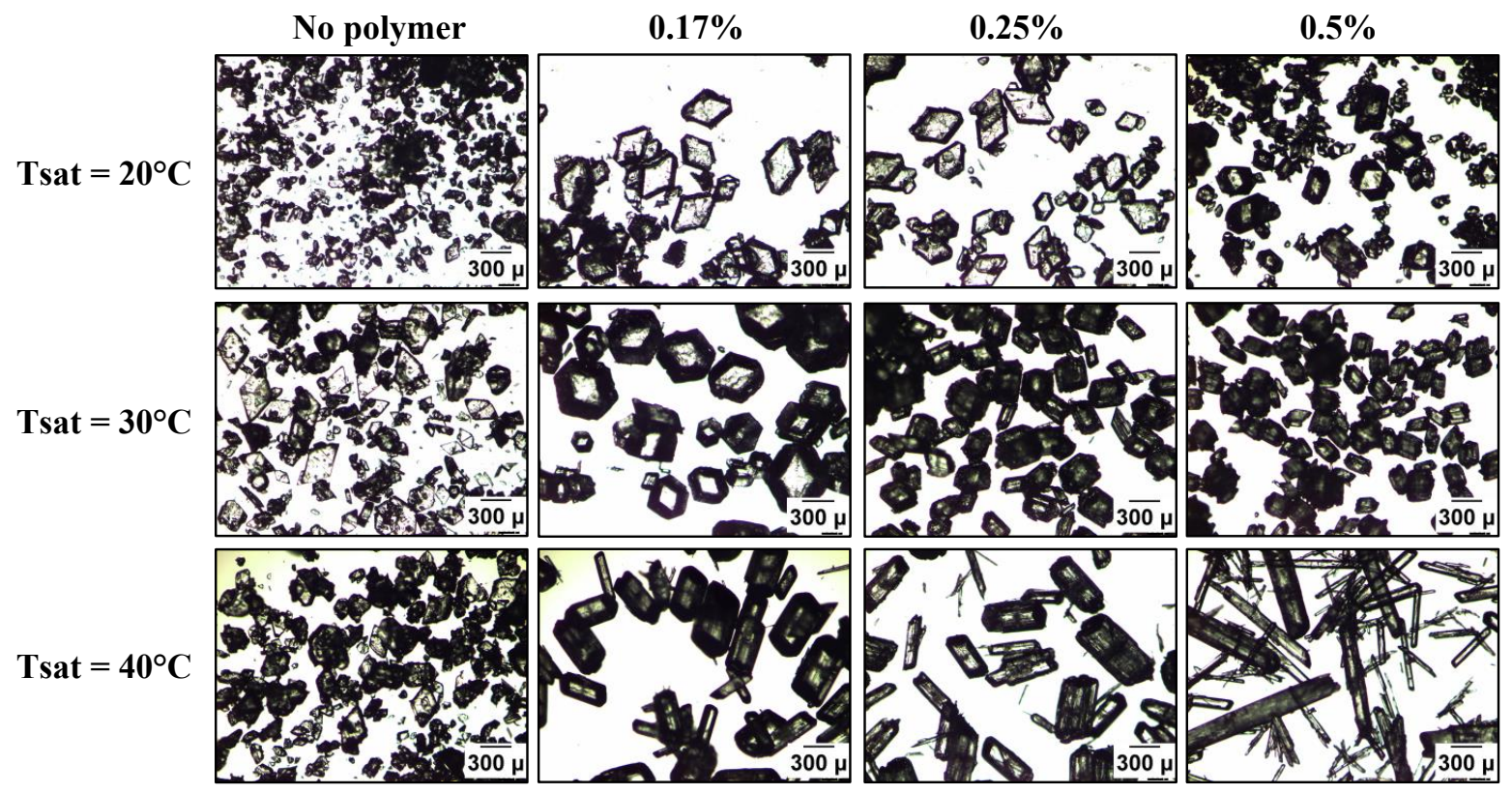

